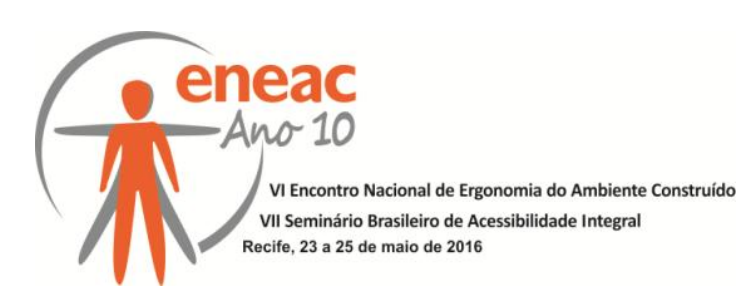

\title{
ACESSIBILIDADE E INCLUSÃO EM ESPAÇOS COLETIVOS DE LAZER
}

\author{
MEDEIROS, Bruna Larine Dantas de (1); \\ NUNES, Talita Cirne (2) \\ (1) UFRN, Graduada em Arquitetura e Urbanismo \\ e-mail: brunadmedeiros@gmail.com \\ (2) UFRN, Graduada em Arquitetura e Urbanismo \\ e-mail: talita.cirne@gmail.com
}

\begin{abstract}
RESUMO
Este artigo procura analisar a influência de equipamentos acessíveis e sua relação com a integração social de pessoas com deficiência ou mobilidade reduzida/limitada em áreas de uso coletivo destinadas ao lazer, neste caso, as praças. Para isso, foram realizados estudos comportamentais e funcionais através de observações "in loco", registro fotográfico, passeio acompanhado e aplicação de questionários que buscaram obter a opinião dos usuários de duas praças da cidade de Natal-RN, e de pessoas com deficiência ou mobilidade reduzida/limitada, acerca da utilização desse tipo de ambiente, das dificuldades encontradas, e dos pontos positivos e negativos de cada equipamento e característica do local. O trabalho aborda a relação entre o espaço público e a cidadania, a partir da análise da acessibilidade nos espaços públicos e das praças enquanto espaços de convívio, trazendo algumas recomendações, com base no que foi desenvolvido e observado ao longo da pesquisa, para que o espaço público possa contribuir na inclusão de pessoas com deficiência ou mobilidade limitada/reduzida, e possa, consequentemente, ser mais utilizado.
\end{abstract}

Palavras chave: acessibilidade; praça; espaço público.

\begin{abstract}
This paper aims to analyze the influence of accessible equipment and its relationship to social integration of people with disabilities or reduced mobility in areas of collective use intended for leisure, in this case, the squares. To do this, were made behavioral and functional studies through observations "in situ", photographic record, accompanied tour and questionnaires that sought the opinion of users in two squares in the city of Natal-RN, and people with disabilities or mobility reduced about the use of that kind of space, the difficulties encountered, and the positive and negative points of each device and feature of the site. The work approaches the relationship between public space and citizenship, based on the analysis of accessibility in public spaces and squares while living spaces, bringing some recommendations, based on what has been developed and observed during the research, so that public space can contribute to the inclusion of people with disabilities or reduced mobility, and be more used.
\end{abstract}

Keywords: accessibility; square; public space. 


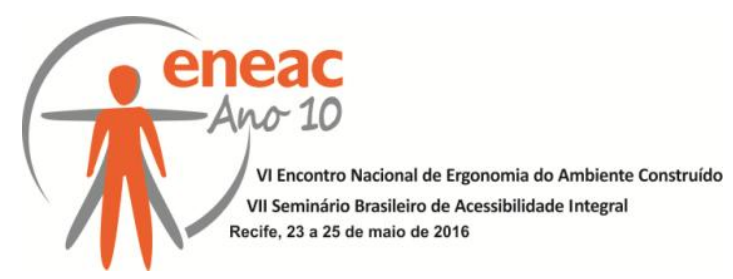

\section{INTRODUÇÃO}

O Município de Natal é pioneiro na elaboração de uma legislação local relacionada à eliminação de barreiras arquitetônicas voltada à promoção de acessibilidade para pessoas com deficiência, a Lei Municipal 4.090/92, regulamentada pelo Decreto Municipal $n^{\circ}$ 5.934/96. A aplicação dessa lei traz contribuições importantes em relação a acesso e circulação no espaço urbano, inclusive da praça, entretanto, não garante sua qualificação como espaço coletivo para ser realmente utilizado por pessoas com deficiência. Partindo desse princípio, é possível identificar diversos exemplares de praças que são acessíveis do ponto de vista da eliminação de barreiras físicas, mas que não são inclusivas, já que, segundo Marta Dischinger et al. (2008):

A inclusão reivindica a noção de pertencer, ocupar e vivenciar o locus. Permitir a inclusão implica numa série de ações combinatórias. Desde chegar a algum lugar de forma independente, segura e confortável; entender a organização e as relações estabelecidas nos lugares; até participar de todas as atividades que ali se desenvolvem. (DISCHINGER et al., 2008, p. 39).

Com a observação do contexto local de utilização e valorização dos espaços coletivos de lazer, percebeu-se que o conceito de acessibilidade aplicado nas praças de Natal parece restringir-se à garantia de acesso e circulação, sem, necessariamente, disponibilizar alternativas de vivência e utilização dos equipamentos e do espaço às pessoas com deficiência ou com mobilidade reduzida.

Segundo Fábio Robba e Sílvio Macedo (2002, p. 11), "praças são espaços livres públicos urbanos destinados ao lazer e ao convívio da população, acessíveis aos cidadãos e livres de veículos". Trata-se de um dos espaços mais tradicionais da cidade, e, no caso das pessoas com deficiência física, devido à dificuldade de mobilidade no tecido urbano, a praça, por seu caráter local, para os bairros que a possuem, torna-se um espaço coletivo com grande potencial para atrair e servir a esses usuários, já que, teoricamente, demanda um menor deslocamento em relação a espaços coletivos de lazer de maior porte, como os shoppings centers, por exemplo. Mas, o que percebemos atualmente na cidade, é que diante da consolidação de outros espaços e atividades de lazer (shoppings centers, parques de diversões, estádios de futebol, televisão), esses espaços tem sido bem menos utilizados.

Levando em consideração esse contexto, chegamos à seguinte indagação: De que maneira a ausência de mobiliário e equipamentos adequados nas praças de Natal interfere na sua utilização pelas pessoas com deficiência física ou mobilidade reduzida/limitada? Então, estudando a relação entre a desqualificação das áreas coletivas e a apropriação e uso do espaço por grupos com mobilidade reduzida ou limitada, temos como objetivo compreender o papel do tratamento urbanístico dos espaços públicos de lazer na inclusão socioespacial de pessoas com deficiência, apontando elementos de base para intervenções no ambiente.

Para que o trabalho pudesse ser realizado de forma mais aprofundada, focamos nossa pesquisa em duas praças - Praça Cívica Pedro Velho e Praça Helio Galvão, que foram escolhidas, principalmente, devido aos equipamentos encontrados, à localização e ao público atuante. A Praça Cívica está localizada no bairro de Petrópolis e sua área de influência é caracterizada por uma multiplicidade de atividades desenvolvidas que vai do ramo da hotelaria, vestuário, gastronomia até o de hospitais. A praça apresenta uma grande área verde, caminhos pavimentadas, bancos, fonte e um ginásio de esporte, que apesar de não ser um equipamento da praça, será avaliado como se fosse, tendo em vista a sua influência na utilização deste espaço público. A Praça Helio Galvão está inserida no conjunto dos Professores, próximo à Universidade Federal do Rio Grande do Norte, no bairro de Capim Macio. Está inserida em uma área com predomínio de uso residencial, e apresenta equipamentos voltados para o lazer de crianças, jovens e adultos. É bem arborizada, iluminada e possui brinquedos infantis, bancos, quadra poliesportiva, além de 


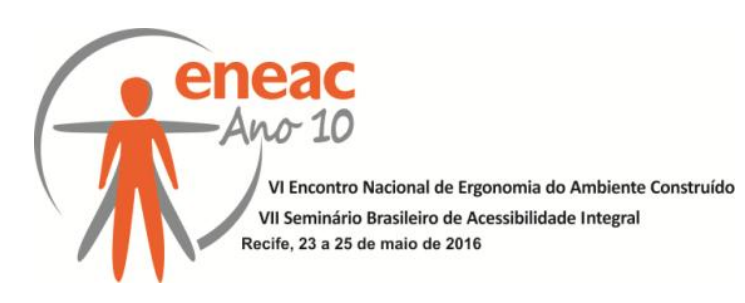

uma igreja recentemente construída no mesmo terreno. Todas as duas praças foram reformadas atendendo algumas normas de acessibilidade, dispondo, principalmente, de rampas de acesso e piso tátil. Os equipamentos de lazer encontrados nessas praças foram implantados de acordo com os padrões seguidos em toda cidade.

A hipótese inicial surgiu com observação de que as praças são espaços de uso coletivo com grande potencial para atrair pessoas com deficiência ou com mobilidade reduzida/limitada, entretanto, esse espaço ainda não é projetado no intuito de garantir seu uso por esse tipo de usuário como espaço coletivo de lazer. Essa utilização poderia ser alcançada através da instalação de equipamentos que propiciem uma maior vivência e integração com o ambiente, não apenas no conceito físico da presença, mas de uma forma ampla e participativa, como espaço de inclusão social. Portanto, a elaboração dessa pesquisa justifica-se pela carência de indagações e estudos que abordem a questão da acessibilidade com enfoque na necessidade de equipamentos adequados dentro dos espaços coletivos de lazer, capazes de inserir pessoas com deficiência física ou com mobilidade reduzida de uma forma ampla e participativa dentro da sociedade.

\title{
2. ESPAÇO PÚBLICO E CIDADANIA
}

O espaço público na cidade assume inúmeras formas e tamanhos, compreendendo desde uma calçada até a paisagem vista da janela. Ele também abrange lugares designados ou projetados para uso cotidiano, cujas formas mais conhecidas são as ruas, as praças e os parques. A palavra "público" indica que os locais que concretizam esse espaço são abertos e acessíveis, sem exceção, a todas as pessoas, como define Sun Alex:

\begin{abstract}
O espaço público é, antes de tudo, o lugar, praça, rua, praia, qualquer tipo de espaço onde não haja obstáculos à possibilidade de acesso e participação de qualquer tipo de pessoa, dentro de regras de convívio e debate. Assim, paradoxalmente, embora o espaço público possa ser também o lugar das indiferenças, ele caracteriza-se, na verdade, pela submissão às regras da civilidade. (SUN ALEX, 2008, p. 12).
\end{abstract}

\subsection{Acessibilidade no espaço público}

O termo acessibilidade é definido pela Associação Brasileira de Normas Técnicas - ABNT (2004, p. 2) como "a possibilidade e condição de alcance, percepção e entendimento para utilização com segurança e autonomia de edificações, espaço, mobiliário, equipamento urbano e elementos". Entretanto, por se tratar de um tema imposto às diversas atividades da vida cotidiana, deve estar inserido em um contexto mais amplo.

Para o desenvolvimento deste trabalho, o enfoque estará na acessibilidade física e arquitetônica, já que diz respeito às relações entre qualificação do espaço das praças e funcionalidade, ocasionalmente complementada pelo conceito de acessibilidade social, decorrente da abordagem de inclusão/exclusão social como consequência das condições de uso desses espaços. Neste trabalho, será considerada a acessibilidade como o conjunto de condições do ambiente, no caso, da praça, que deve permitir a sua utilização por quaisquer pessoas, tenham elas deficiência e dificuldade de locomoção ou não. Essa utilização do espaço deveria incluir oportunidades de interação com o ambiente (edificado ou natural), além de permitir que todos se deslocassem com conforto, segurança e autonomia.

É importante lembrar que, especialmente em projetos urbanos e de uso coletivo, outros fatores, além dos princípios do desenho universal e da acessibilidade arquitetônica, que servem de orientação para uma otimização em relação à inclusão, devem ser considerados, 


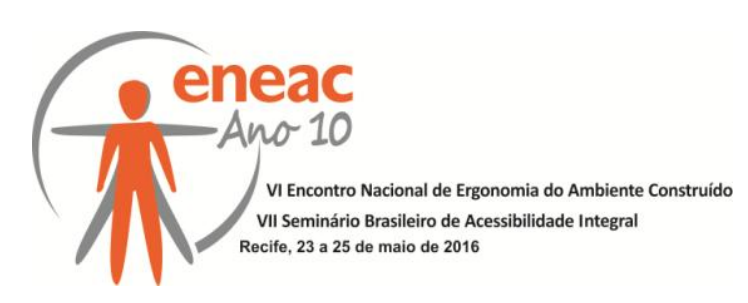

como a adequação cultural, de meio ambiente, a segurança, aspectos econômicos, de estrutura, e estética.

\subsection{A praça como espaço de convívio e inclusão}

Pensar o espaço público nas cidades contemporâneas apresenta-se como tema de grande importância para a sociedade atual, pois os moradores das áreas urbanas estão perdendo gradativamente o espaço vital, o que interfere diretamente na sua qualidade de vida. Segundo Dália Lima (2006, p. 61), o espaço público apresenta um importante papel político, pelo seu caráter relacional entre as pessoas, e concretiza-se fisicamente por ser local acessível a todos, como; praças, ruas, praias, etc, qualquer tipo de espaço onde não haja barreiras a possibilidades de acesso e participação de qualquer pessoa, onde as regras do convívio e o debate devem ser respeitados.

Dessa forma, a quantidade e a qualidade dos equipamentos e mobiliário urbano tornam-se fundamentais para a sua utilização, sobretudo quando tais aparatos são adaptados e direcionados às características dos usuários, de modo que a carência de elementos capazes de oferecer o mínimo de conforto para que idosos, deficientes físicos, visuais e auditivos, contribui para o abandono destes espaços. Portanto, o lugar deve dispor de uma estrutura capaz de atrair usuários de todas as idades (experiências sociais), dispondo de elementos físicos que atendam as mais variadas atividades em um maior espaço de tempo (flexibilidade/variedade), concorrendo para que o local permaneça ocupado, pois sua ociosidade seria desperdício de infraestrutura. Além disso, o espaço deve permitir que o usuário, desenvolva sua criatividade, seu senso de companheirismo e de participação, exercitando sua cidadania e sua sociabilidade em um espaço público.

Os espaços públicos, inclusive as praças, são lugares onde as relações de proximidade podem ganhar um maior conteúdo comunicacional. Como afirma Lima (2006, p.65), "é nesses locais que com maior clareza apresentam-se situações variadas, pessoais ou sociais, econômicas e culturais, e onde as carências de vários tipos se evidenciam". Porém, o intercâmbio é condicionado pelas infraestruturas presentes e suas normas de utilização, pelas possibilidades de vida cultural local e pelos equipamentos existentes. Nesse sentido, fica claro que os equipamentos e mobiliário urbano são fundamentais para a aceitação de um espaço público e para sua caracterização como elemento de prestação de serviço à comunidade. Devido à sua importância no contexto deste trabalho, torna-se essencial definilos.

Segundo Alex (2006, p.18), "os espaços públicos são paisagens participativas, e o controle do usuário pode ser compreendido com base nas cinco dimensões propostas por Kevin Lynch para construir 'bons' ambientes: presença, uso e ação, apropriação, modificação e disposição". A presença é o direito de acesso a um lugar, e sem ela o uso e a ação não são possíveis. Uso e ação referem-se às habilidades das pessoas de utilizar um espaço. Com a apropriação, os usuários tomam posse de um lugar, simbolicamente ou de fato. Modificação é o direito de alterar um espaço para facilitar o seu uso, e disposição é a possibilidade de desfazer-se de um espaço público. Portanto, estudar praças como espaços indispensáveis à vida pública representa um duplo desafio: a adoção de conceitos de cidadania e democracia desenvolvidos por outros campos de estudos sociais. É nesse sentido que pesquisas, observações e entrevistas com usuários são meios que contribuem para a melhor compreensão do espaço, podendo indicar caminhos para atender às necessidades humanas. 


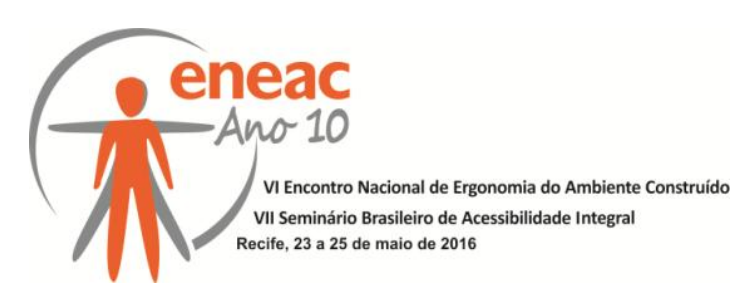

\section{MÉTODO DE PESQUISA}

Esta pesquisa utilizou elementos fundamentais para viabilizar a avaliação e a análise do espaço de duas praças de Natal, com ênfase na valorização da experiência do usuário na identificação, tanto das barreiras arquitetônicas, quanto das necessidades de incentivo e atrativo nos espaços coletivos de lazer, foco principal desta pesquisa.

A pesquisa de campo baseou-se em uma breve avaliação pós-ocupação (APO), com ênfase na aplicação de questionários aos usuários de duas praças previamente escolhidas, aplicação de questionários em três instituições que atendem a pessoas com deficiência, e o passeio acompanhado (uma pessoa com deficiência motora e três pessoas com deficiência visual, em ambas as praças analisadas). Com base nos conceitos de APO - conceito mais se adequa aos objetivos do presente trabalho -, foram obtidas informações referentes à opinião dos usuários e/ou agentes que participam da dinâmica das praças escolhidas. Essas informações foram obtidas principalmente através dos seguintes métodos: observação, questionários, e registro fotográfico.

\subsection{Aplicação dos questionários}

Foram aplicados 30 questionários a pessoas encontradas nas praças Hélio Galvão e Pedro Velho; e 30 questionários a pessoas com deficiência, nas seguintes instituições: Associação de Pais e Amigos dos excepcionais (APAE Natal), Instituto de Educação e Reabilitação de Cegos de Natal e Sociedade Amigos do Deficiente Físico (SADEF). Às pessoas abordadas nas praças foram feitos questionamentos focados principalmente nas praças em que elas se encontravam. Nos questionários realizados nos institutos foram feitas perguntas voltadas para qualquer praça que o entrevistado já tivesse frequentado em Natal. A abordagem foi realizada em diferentes horários (manhã, tarde e noite) e em diferentes dias da semana, de forma a criar um perfil bastante diversificado dentro da abordagem do tema. Enfim, após recolher todas as informações necessárias, através dos registros fotográficos, das observações in loco, e dos questionários efetuados com os usuários das praças e as pessoas com deficiência, nas instituições, os dados foram reunidos através da leitura e elaboração de gráficos, e analisados, para verificar se as interpretações comprovam, ou não, a hipótese desta pesquisa.

\subsection{Passeio acompanhado}

O passeio acompanhado tem como finalidade conhecer o modo como a pessoa com deficiência (nesse caso, visual ou motora) se relaciona com o ambiente, e como se comporta diante de barreiras arquitetônicas. Envolve a observação do comportamento do usuário e da observação do ambiente por ele, buscando identificar problemas referentes à acessibilidade.

Foram realizados dois passeios acompanhados, em cada praça avaliada, sendo um com pessoa com deficiência motora (usuário de cadeira de rodas), e outro com três pessoas com deficiência visual (perda total da visão ou deficiência visual severa, todos usuários de bengala). Os percursos ocorreram em áreas de uso comum nas duas praças, cujo destino a ser alcançado estaria sujeito a variações, de acordo com a ocasional solicitação dos participantes, não importando a ordem dos acontecimentos. Foram fixados alguns locais a serem percorridos como: Acesso às praças; equipamentos variados, como bancos, lixeiros, telefones públicos e paradas de ônibus, quando existentes, quadras e parques. No decorrer do percurso, as pessoas com deficiência foram incentivados a desenvolver atividades relacionadas ao cotidiano e a relatar as dificuldades encontradas durante os deslocamentos, 


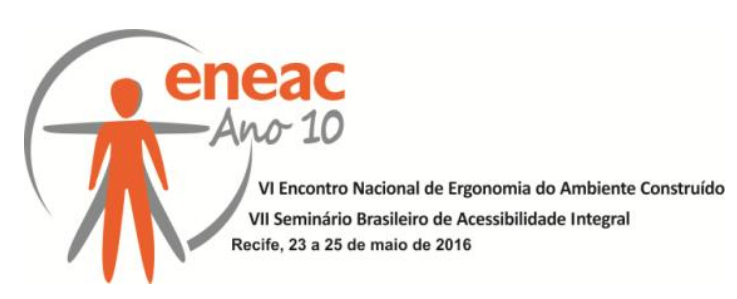

enquanto as questões envolvidas no processo iam sendo transcritas e fotografadas pelas pesquisadoras.

\section{RESULTADOS}

\subsection{Análise da aplicação de questionários}

Foram aplicados 30 questionários aos usuários das praças Pedro Velho (cívica) e Hélio Galvão, sendo 15 questionários para cada praça. 100\% dos entrevistados afirmaram não ter nenhuma deficiência ou dificuldade de locomoção. Porém, como já foi dito anteriormente, é considerável o número de pessoas idosas e acompanhadas com crianças pequenas, um fato favorável ao desenvolvimento deste trabalho, já que, teoricamente, essas pessoas têm uma maior sensibilidade acerca das dificuldades de utilização do espaço público, incluindo seus equipamentos e mobiliário. Além disso, também foram aplicados 30 questionários com pessoas com deficiência ou mobilidade reduzida, em três instituições.

Analisando os dados e gráficos obtidos, chegamos à conclusão de que há diferenças e semelhanças de utilização e percepção do espaço por pessoas com deficiência ou dificuldade de locomoção e pelas pessoas que não apresentam esse tipo de limitação. Um exemplo significativo é a semelhança entre os resultados dos gráficos que indicam a preferência por certos locais de lazer. Em ambos os tipos de questionários, o local de maior preferência entre os entrevistados foram os shoppings e as praias. Os entrevistados ainda afirmaram, através de conversas informais, que o diferencial do shopping ocorre principalmente devido à melhor segurança e a maior facilidade de locomoção e adaptação desses lugares em comparação com os locais públicos, onde a maioria dos equipamentos e passeios não são bem cuidados.

\section{Gráfico 01: Preferência entre os locais de lazer}

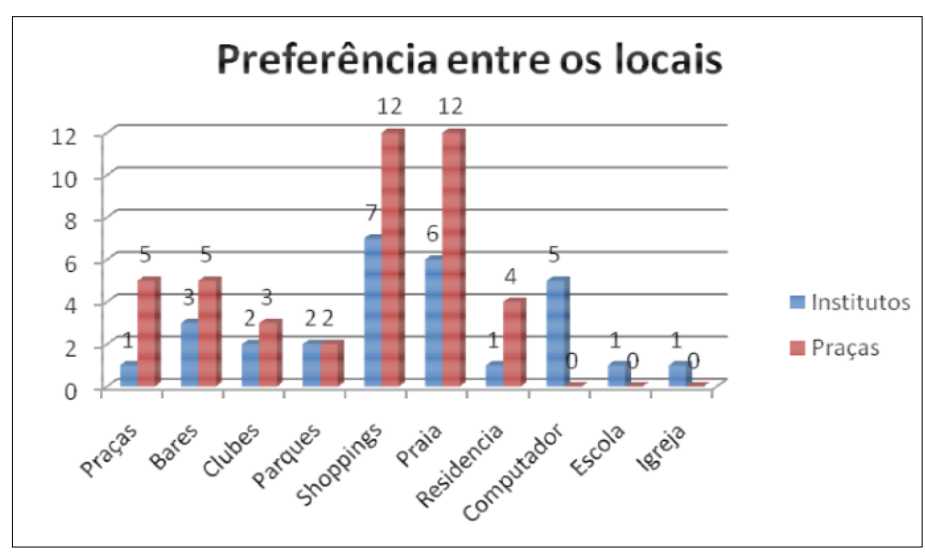

Fonte: Elaborado pelas autoras

Quanto ao meio de transporte utilizado para chegar às praças, ambos os perfis também mostraram resultados semelhantes. O transporte coletivo é o meio de transporte mais requisitado e utilizado. Essa conclusão evidencia a necessidade de ônibus adaptados, com linhas mais regulares. Os relatos orais feitos por pessoas com deficiência motora durante a aplicação dos questionários e do passeio acompanhado revelaram que o sistema de transporte adaptado a esses tipos de condição física ainda precisa ser expandido e mais 


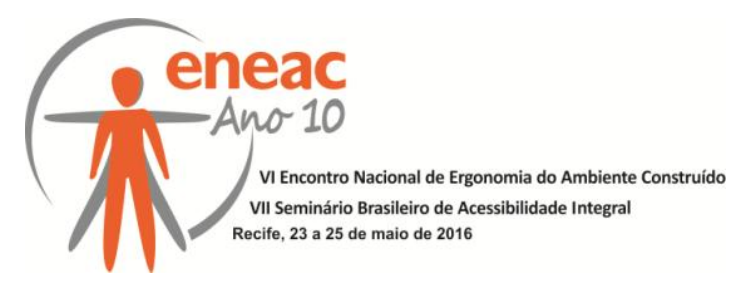

bem organizado, pois mesmo que as praças disponibilizem opções de lazer, muitas vezes o transtorno de chegar até elas não compensa a participação nas atividades que nelas são desenvolvidas. O que se faz necessário, nesse caso, e em todo o campo relacionado à inclusão, são ações combinadas.

As pessoas com deficiência se mostraram mais sensíveis para avaliar as ruas e calçadas próximas às praças que frequentam. Segundo elas, esses espaços normalmente encontramse em péssimo estado de manutenção, sem possibilidade de tráfego seguro por pessoas com deficiência motora, principalmente. Mesmo que o enfoque do trabalho não seja a questão da acessibilidade somente como acesso e circulação, é importante citar o contraste entre os resultados obtidos para os dois tipos de usuários. Para as pessoas sem deficiência ou mobilidade reduzida/limitada, as ruas e calçadas das praças em que frequentavam na ocasião da aplicação dos questionários apresentam boa qualidade. Muitos responderam que as ruas e calçadas eram bem cuidadas, não possuíam grandes desníveis e "as calçadas eram acessíveis, pois possuíam rampas". Nesse ponto ficou claro que quem vivenciava o problema estava muito mais sensível para avaliá-lo.

Diante do questionamento se as praças são ou não inclusivas, também podemos perceber uma certa diferença entre as respostas dos diferentes usuários. Nos questionários aplicados nas praças, $77 \%$ dos entrevistados afirmaram que as mesmas são inclusivas, e que essa inclusão ocorre devido à presença de rampas de acesso e o piso tátil, já mencionados anteriormente. Porém, $53 \%$ dos entrevistados nas instituições, isto é, pessoas com deficiência, acreditam que apesar de muitas vezes as rampas realmente existirem, elas, sozinhas não são responsáveis por promover a inclusão. Muitos usuários sentem falta de uma melhor manutenção das ruas e calçadas, o que dificulta o seu acesso, falta de meios de transporte para usuários de cadeiras de rodas, principalmente, e brinquedos seguros que permitam a utilização de pessoas com deficiência, que foi o principal ponto de reclamação das crianças, especialmente as cadeirantes.

Assim, percebemos que a noção de inclusão, para as pessoas que não apresentavam nenhuma limitação física, era muito mais simples, de modo que a presença de rampas e piso tátil fosse suficiente para que um espaço fosse considerado inclusivo. Já as pessoas com deficiência ou dificuldade de locomoção apresentaram uma noção muito mais ampla, sempre relacionando a inclusão com a possibilidade de utilização do espaço, de forma segura e com o mínimo possível de diferenciação em relação aos outros usuários.

\subsection{Análise do passeio acompanhado}

A metodologia do passeio acompanhado permitiu a observação do comportamento dos usuários da praça, nesse caso, pessoas com deficiência física, e sua interação com o ambiente. Para isso, foi definido um percurso para cada praça (figuras 01 e 02), de modo que contemplasse diferentes pontos, equipamentos e mobiliários. Dessa forma, conseguimos não só identificar problemas referentes à acessibilidade, mas também vivenciar as dificuldades de inclusão desses usuários, convidados a nos relatar a sua percepção sobre as condições de uso das praças.

Inicialmente, para compreender a interação de deficientes visuais com o espaço das praças, foi realizada a primeira etapa do passeio acompanhado, contando com a participação de três estudantes do Instituto de Educação e Reabilitação de Cegos do Rio Grande do Norte, usuários de bengala. Essa etapa da pesquisa, referente aos deficientes visuais, foi realizada em duas manhãs, de modo que, durante a primeira manhã, foi realizado o passeio na Praça

Pedro Velho (Praça Cívica); na segunda manhã, o passeio foi na Praça Hélio Galvão. A segunda etapa do passeio acompanhado refere-se à realização do percurso por uma pessoa com deficiência motora, contando com a participação de um usuário de cadeira de 


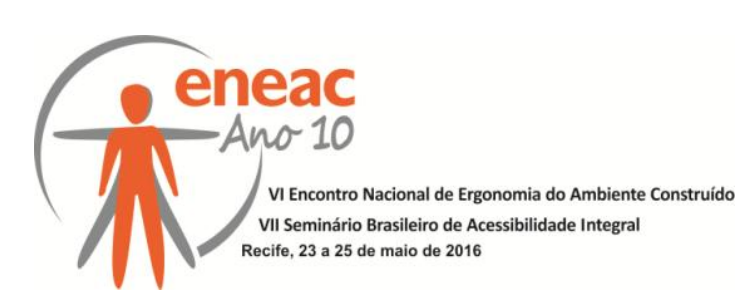

rodas, que visitou as duas praças em uma mesma tarde. Todas as visitas ocorreram no mês de outubro de 2009.

Figura 01: Planta baixa esquemática da Praça Hélio Galvão, com traçado do percurso desenvolvido para aplicação de questionários e passeio acompanhado.

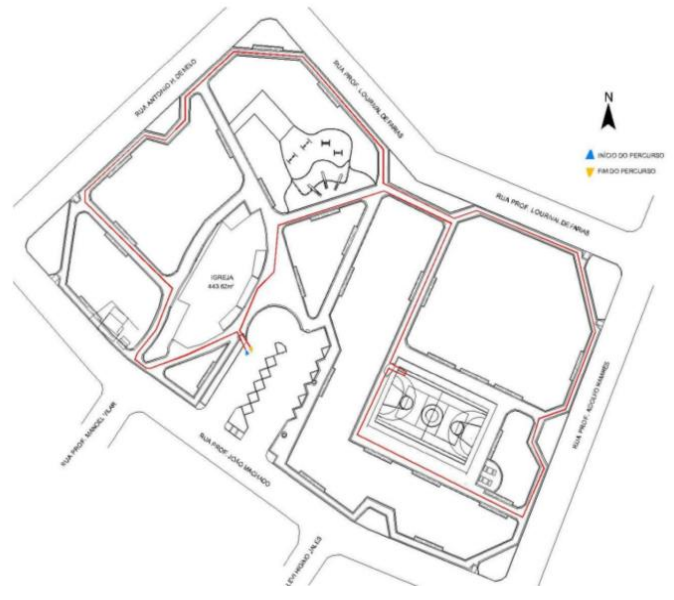

Fonte: SENSUR-Natal (2009).

Nota: Trabalhado pelas autoras (2009).

Figura 02: Planta baixa esquemática da Praça Pedro Velho (Praça Cívica), com traçado do percurso desenvolvido para aplicação de questionários e passeio acompanhado.

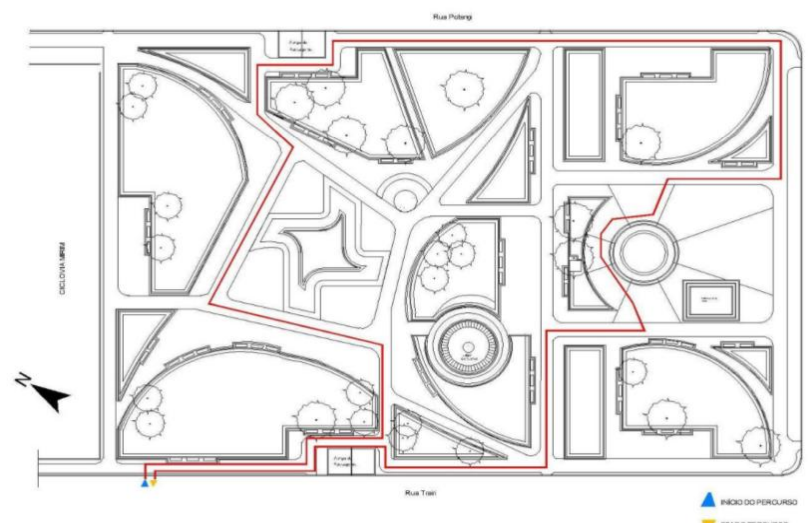

Fonte: Sobre bases cartográficas da SENSUR-Natal (2009) Nota: Trabalhado pelas autoras

a) Pessoas com deficiência visual - Praça Hélio Galvão

O percurso iniciou-se pelo estacionamento, localizado na própria praça. O primeiro item que pudemos perceber foi a presença do piso tátil, que, apesar de presente, segundo os participantes do passeio, apresentava relevos muito "rasos", dificultando a diferenciação em relação ao piso normal (figura 03). Além disso, o piso é ausente em alguns pontos da praça, como por exemplo, no acesso ao parque. Segundo os voluntários, apesar de que em muitos lugares a legislação municipal não exija esse item, ele auxilia satisfatoriamente a circulação de pessoas cegas (e com bengala) por determinado ambiente. A quadra, apesar de não ser bem cuidada e apresentar equipamentos quebrados e sujos, é de fácil acesso para pessoas com deficiência visual, uma vez que não existem barreiras que dificultem a entrada/saída 


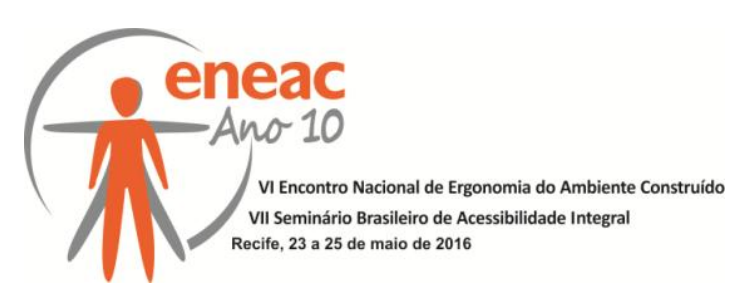

por esses usuários. Além disso, as passagens se encontram bem próximas às arquibancadas, facilitando a orientação. Alguns problemas encontrados nessa praça, além do piso tátil com relevo pouco contrastante é a falta de acessos fáceis que interliguem diferentes setores. Um exemplo disso é o caso de uma pessoa que esteja utilizando a quadra e precise se dirigir ao estacionamento central. Ela acaba tendo que percorrer um caminho maior para chegar de um canto ao outro, o que ocasionaria que algumas pessoas preferissem passar sobre a grama. Esse caminho mais extenso a ser percorrido também dificulta a orientação de uma pessoa com deficiência visual.

Figura 03: Piso tátil pouco eficiente

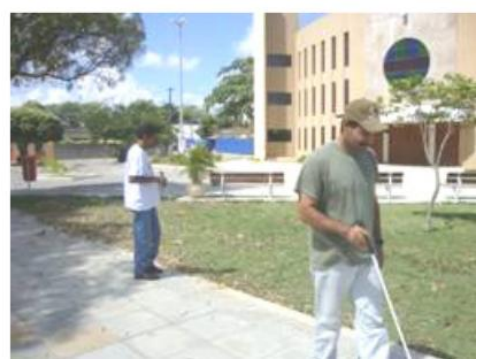

Fonte: Acervo da pesquisa (2009)
Figura 04: Parque infantil

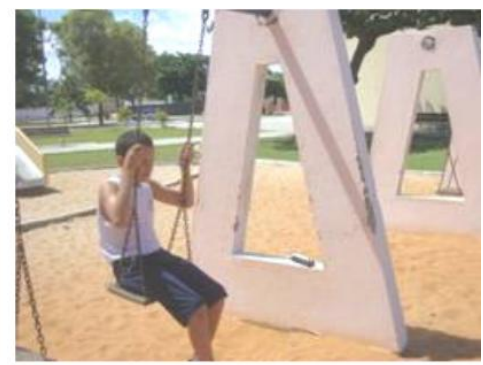

Fonte: Acervo da pesquisa (2009)

\section{b) Pessoas com deficiência visual - Praça Pedro Velho (Praça Cívica)}

A primeira dificuldade encontrada foi a de circular pelas calçadas localizadas fora da praça, no seu entorno, por onde foi necessário passar para chegar ao ponto de partida do passeio acompanhado. As calçadas eram irregulares, ocupadas por quiosques de venda de alimentos que ocupavam o acesso à rua com mesas e cadeiras, dificultando a locomoção. Além dos problemas que acabamos de citar, as ruas também contam com problemas de esgotamento sanitário e falta de manutenção.

A praça apresenta dois tipos de piso, além do piso tátil. Essa diferenciação entre pisos, sendo um liso e outro irregular, tem uma implicação, que segundo os participantes do passeio, acaba contribuindo para a circulação. O piso liso se destaca em relação ao irregular (em pedra portuguesa), e é utilizado como piso principal de circulação, uma vez que é o responsável por direcionar o usuário a vários os pontos de acesso à praça além de tangenciar todos os equipamentos e mobiliários presentes na mesma. De acordo com os participantes, o contorno do piso tátil nos bancos é um detalhe que funciona muito bem, pois chama a atenção para a presença de uma barreira. Os bancos também estão, de acordo com os voluntários, bem localizados e a proximidade de vários bancos permite uma melhor interação com outros usuários. Os voluntários também apontaram sobre a presença de sombreamento nos bancos, permitido pela presença de muitas árvores. Outro detalhe importante é a sinalização dos canteiros, através de cercados e muretas. Esse detalhe, juntamente com o piso tátil permite a percepção da interrupção do passeio. A proximidade das plantas com o passeio também possibilita que as pessoas as toquem sem precisar subir a grama.

No momento da visita, a fonte presente na praça estava desligada, o que dificultou um pouco sua identificação imediata. Quando em funcionamento, a fonte possibilita, além da percepção pelo tato, a identificação através dos sons, estimulando outros sentidos. Uma dificuldade encontrada na praça foi a forma como a decoração natalina foi colocada, constituída por uma árvore de natal improvisada em área de livre passagem, com linhas grossas decoradas com fitas, presas ao piso através de pregos (figura 06) e sem apresentar nenhuma sinalização, colocando em risco pessoas desatentas ou com deficiência visual, 


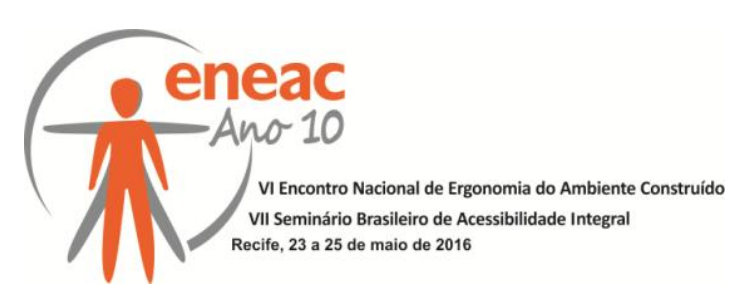

que poderiam tropeçar ou sofrer algum acidente. A praça também apresenta alguns problemas de manutenção e vandalismo, como pisos quebrados equipamentos danificados.

Figura 05: Diferenciação de piso (comércio ao fundo)

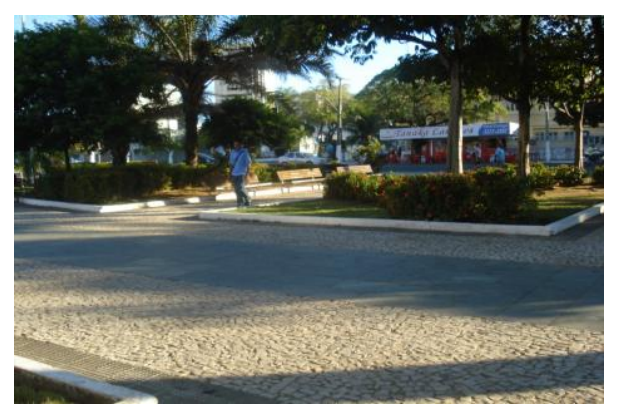

Fonte: Acervo da pesquisa (2009)
Figura 06: Árvore de Natal

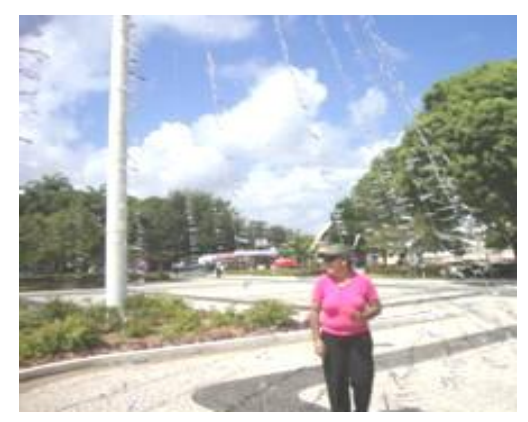

Fonte: Acervo da pesquisa (2009)

Foi observado que alguns equipamentos apresentam barreiras projetadas com finalidade estética ou, talvez, para dificultar ações de vandalismo, que acabaram dificultando sua identificação por esses usuários. Um exemplo disso é a estátua em homenagem a Pedro Velho. A altura da estatua (sobre um pedestal) facilita sua visualização para transeuntes de qualquer ponto da praça, porém, impossibilita sua identificação e manipulação por pessoas que não possuem a visão e necessitam do tato para fazer esse reconhecimento. A parte da estátua que poderia permitir algum acesso apresenta uma barreira criada com a própria vegetação.

\section{c) Pessoas com deficiência motora - Praça Hélio Galvão}

O passeio acompanhado teve início no estacionamento, que não apresentava demarcação de vaga acessível, nem sinalização, e cujo piso de paralelepípedos causava trepidação na cadeira de rodas. $O$ acesso do estacionamento ao piso da praça se deu por meio de uma rampa, com inclinação adequada, e que, segundo o cadeirante, não representou um obstáculo ao percurso. Em seguida, logo que começamos a contornar a praça, foram identificados mobiliários básicos, como lixeiros e bancos, que atendiam às dimensões de alcance e utilização. Ao passar pela lateral do parque infantil, foi observado que há um acesso pavimentado à área de parque, mas que os equipamentos (brinquedos) localizam-se na areia e não são adaptados para pessoas cadeirantes (figura 07). Seguindo o percurso, foi identificado um ponto positivo na praça, a arborização, que torna o ambiente mais confortável e pode servir de atrativo para uso do espaço. Também foi chamada atenção para a localização do telefone público (figura 08), que além de não apresentar dimensão adequada para alcance, estava locado em uma área gramada, com um obstáculo à sua frente, sendo, portando, inadequado ao uso.

Foram apontadas outras duas opções de lazer presentes nessa praça: as mesas de jogos de tabuleiro e a quadra poliesportiva. As mesas atendiam às condições de alcance e aproximação, e foram apontadas como um mobiliário muito interessante para atender ao público de todas as idades, em especial jovens e adultos, inclusive os usuários de cadeira de rodas. Ao sairmos da área de mesas, nos deparamos com a quadra poliesportiva, que apresenta duas entradas, sendo uma delas nivelada, possibilitando acesso e utilização desse equipamento, que foi apontado como um potencial espaço de lazer. O que pode dificultar o uso desse equipamento é a inexistência de local adequado para cadeirantes na área de arquibancada. Ao longo de todo o percurso, encontramos bancos de madeira, que 


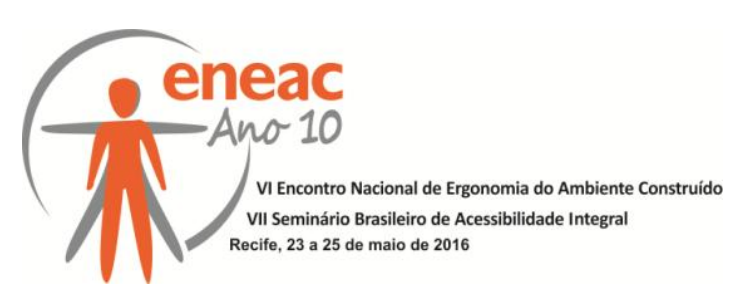

também serviam como equipamento de lazer, já que permitiam atividades de convivência. Por fim, o último equipamento observado no percurso foi a Igreja implantada na praça, cujo acesso se dava por meio de uma rampa com inclinação adequada. Esse é um equipamento que pode funcionar muito bem para a utilização da praça, graças à sua capacidade de agregar pessoas naquele espaço, ao permitir atividades de convivência e lazer. É importante lembrar que toda a área de piso da praça é composta por piso intertravado e tátil, que encontra-se em bom estado de conservação, o que facilitou a realização do percurso. $O$ passeio foi concluído com uma avaliação positiva do espaço, embora tenha sido apontada a necessidade de um maior número de atrativos para pessoas com deficiência.

Figura 07: Parque infantil

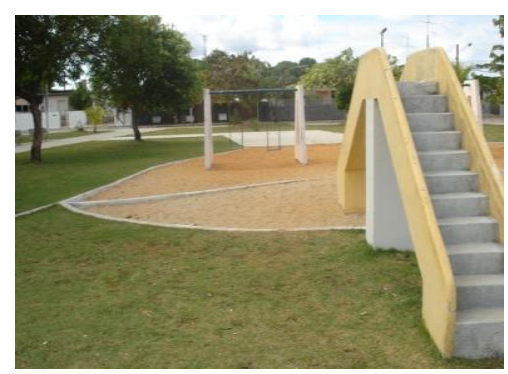

Fonte: Acervo da pesquisa (2009)
Figura 08: Telefone público inacessível

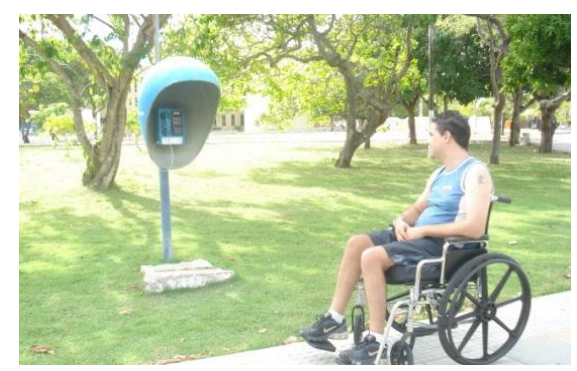

Fonte: Acervo da pesquisa (2009)

\section{d) Pessoas com deficiência motora - Praça Pedro Velho (Praça Cívica)}

A Praça Cívica, ao contrário da Hélio Galvão, não apresenta um bolsão de estacionamento, e os carros, então, estacionam ao longo do contorno da praça, sem delimitação de vaga, nem sinalização. O percurso teve início com o acesso à praça por meio de uma rampa com inclinação e sinalização adequada, porém com locação errada (no meio da testada do lote). Seguimos o percurso pelo caminho definido pelos canteiros e pelo piso diferenciado, formado por uma sequencia de pedras regulares em contraste com a superfície de pedra portuguesa. No caso da locomoção na cadeira de rodas, a faixa de pedras regulares representou a faixa adequada para se deslocar, enquanto a superfície em pedra portuguesa provocou trepidações e dificultou a locomoção na cadeira de rodas (figura 09). Ainda assim, logo no início do percurso, a falta de manutenção desses dois tipos de piso gerou obstáculos que dificultaram o percurso (figura 10), e que voltaram a aparecer em outros pontos do passeio. Seguindo, encontramos a parada de ônibus, que, por se localizar na própria praça, não apresentava nenhum obstáculo/desnível. Ao passar pelas proximidades ao cruzamento das ruas Potengi e Prudente de Morais, foi identificado um obstáculo na faixa de pedestres, que mesmo não fazendo parte da praça, acabava prejudicando o acesso a ela, e, consequentemente, seu uso.

Figura 09: Diferenciação do piso

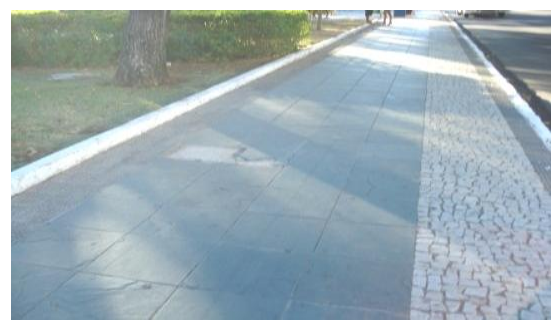

Fonte: Acervo da pesquisa (2009)
Figura 10: Falta de manutenção

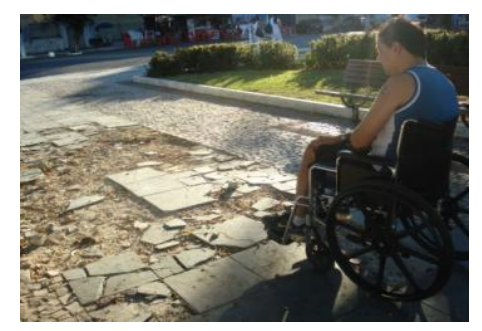

Fonte: Acervo da pesquisa (2009) 


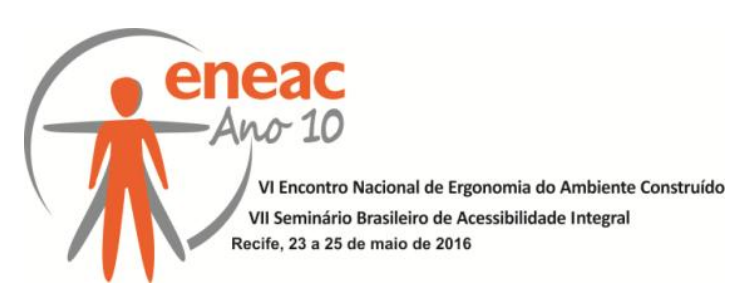

Foram sendo observados bancos distribuídos por toda a praça, que, assim como na Praça Hélio Galvão, possibilitam atividades de convivência e contribuem para a utilização do espaço. Foi constatado que esta praça, em relação à praça Hélio Galvão, apresenta mais opções de lazer, que se referem aos bancos, ao ginásio de esportes (que não foi incluído no passeio acompanhado pois encontrava-se fechado) e a alguns pontos de vendas de alimentos, cujas mesas apresentavam condições de alcance e utilização. O passeio foi concluído com uma avaliação regular do espaço, apresentando menos manutenção que a Praça Hélio Galvão.

\section{CONSIDERAÇÕES FINAIS}

Levando em consideração nossa questão problema: "De que maneira a ausência de mobiliário e equipamentos adequados nas praças de Natal interfere na sua utilização pelas pessoas com deficiência física ou mobilidade reduzida/limitada?", podemos constatar que a falta de equipamentos adaptados às diferentes necessidades e mobiliários acessíveis e seguros para todos, resulta em uma utilização pouco proveitosa desse ambiente coletivo de lazer. Dessa forma, a hipótese inicial é confirmada, pois, ao fim da pesquisa constatamos que o espaço da praça ainda não é projetado de modo a garantir seu uso por esse tipo de usuário como espaço coletivo de lazer. Para que isso pudesse ocorrer seria necessário um conjunto de ações integradas, para possibilitar a inclusão no espaço público da praça. É evidente a importância de equipamentos e atividades que promovam a vivência desse espaço, propiciando a realização de atividades em que haja o maior número possível de estímulos aos sentidos, trabalhando as diversas deficiências por meio da cooperação e da integração entre as pessoas, potencializando as diferentes capacidades de cada uma.

Entretanto, essas medidas de valorização do espaço físico da praça só funcionarão realmente bem se todo o conjunto de condições às quais a pessoa com deficiência está submetida antes, durante e depois de utilizar a praça também estiverem contribuindo para a inclusão. Nesse sentido, se reafirma a importância de boas condições de mobilidade urbana e de acesso e circulação na praça, como medidas de qualificação espacial, mas que não dispensam a existência de atrativos, sejam eles atividades ou equipamentos, para garantir a dinâmica de utilização desse espaço, e cumprimento do papel do espaço público na inclusão social de pessoas com deficiência ou mobilidade reduzida.

\section{REFERÊNCIAS BIBLIOGRÁFICAS}

ALEX, Sun. Projeto da Praça. São Paulo: Senac, 2008.

ASSOCIAÇÃO BRASILEIRA DE NORMAS TÉCNICAS (ABNT). NBR 9050: acessibilidade de pessoas portadoras de deficiências a edificações, espaço, mobiliário e equipamentos urbanos. Rio de Janeiro: ABNT, 1994.

DISCHHINGER, Marta; SAVI, Aline; SILVA, Leonora; INNECCO, Carolina. Incluir brincando. Inclusão, Brasília, v. 4, n. 2, p. 38-45, jul./out. 2008

LIMA, Dália Maria Maia Cavalcanti de. $O$ espaço de todos, cada um no seu lugar: o uso dos espaços públicos destinados ao lazer em Natal. Tese (doutorado), Programa de PósGraduação em Ciências Sociais, UFRN, Natal/RN, 2006.

NATAL. Lei $n^{\circ} 4.090$ de 03 de julho de 1992. Dispõe sobre a eliminação de barreiras arquitetônicas. Disponível em: <http://natal.rn.gov.br/semurb>. Acesso em: 03 set. 2009.

ROBBA, Fábio; MACEDO, Silvio Soares. Praças Brasileiras. São Paulo: Editora da Universidade de São Paulo: Imprensa Oficial do Estado, 2002. 